\author{
Military Technical College \\ Kobry El-Kobbah, \\ Cairo, Egypt
}

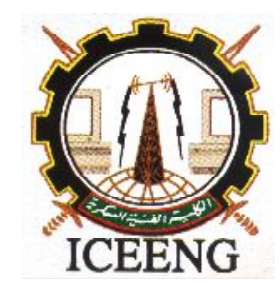

$9^{\text {th }}$ International Conference on Electrical Engineering ICEENG 2014

\title{
Power Factor Correction for Three Phase Induction Motor Drive System
}

\author{
By \\ Haitham.Z.Azazi, E. E. EL-Kholy, S.A.Mahmoud and S.S.Shokralla *
}

\section{$\underline{\text { Abstract: }}$}

This paper presents the study of a three phase PWM inverter-fed induction motor drive with single phase utility input, with and without a power factor correction circuit (PFC). The PFC circuit is controlled with the proposed predictive current control. The effects of the PFC circuit on the magnitude of the input current, harmonic contents and input power factor of the A.C drive system are studied. The Fast Fourier Transform (FFT) is used to get the frequency spectrum of the current waveforms. A comparative study of simulation and experimental results for the A.C. drive system, with and without PFC circuit, is carried out. The experimental implementation of PFC control of the boost converter controlled three-phase IM drive system, with FOC principles in real time, using DSP controller board DS1104 is achieved using the proposed predictive control. The proposed PFC control method used to achieve a low input line current harmonics, for obtaining a good power quality with a fast dynamic response for output voltage and line current.

\section{Keywords:}

Converter control, Power factor correction, Total harmonic distortion (THD), predictive current control, field oriented control.

* Electrical Engineering Department, Faculty of Engineering, Menoufiya University. 


\section{Introduction:}

The use of variable speed drive (VSD) systems in the industry is growing due to emerging high volume of fractional horsepower VSD applications. All VSDs have rectifiers and storage capacitors in their front-end to get dc voltage from an ac power source. This input circuitry lowers the power factor (PF) of the VSD systems and pollutes ac power systems. In variable speed drive systems, the inputs current is distorted and out of phase the input voltage. In this case, the power factor is less than unity and less real power is transmitted to the load. However, the R.M.S value of input current is increased, due to harmonic currents [1-2]. Low power factor gives rise to a number of serious problems in variable speed drive systems. The size of input fuses and circuit breakers of input circuitry must be increased, beside the distorted current waveform, which causes interference with the other equipment, must be filtered to reduce magnitudes of harmonic frequencies [3-4].

Also, due to the emerging requirements in the drive applications for high efficiency and low cost coupled a sinusoidal current operation from the utility are necessary. The study of power factor correction (PFC) integrated with inverter-fed induction motor drives become very important. Generally, a single phase uncontrolled diode bridge rectifier is used to feed the inverter of $\mathrm{AC}$ motor, but this converter has the following disadvantages: uncontrolled DC-link voltage, poor input power factor, Harmonics in the $\mathrm{AC}$ mains, disturbance in the nearby system. Majority of industrial drives use electric motors, since they are controllable and readily available. [5-7].

The increasing interest today is to find compact and inexpensive variable speed drives. There are several different approaches to improve the input power factor and the input current harmonics of the VSD systems [8-9]. These approaches employ a frontend converter for PFC and an inverter for the three-phase induction motor (IM), or a converter for permanent magnet brushless dc motor (PMBDC) and switched reluctance motor (SRM). The non-isolated drive system employs a non-isolated PFC of the boost converter as input to the PWM inverter as proposed in [9-11]. Steady-state performance of a three-phase, medium-power ac motor operated from a single-phase ac source using a diode bridge rectifier, with boost converter has been discussed in references [12-15].

Most of the existing digital PFC control methods are based on conventional analog control laws. They basically implement the analog control laws in a digital format [1618]. In conventional digital implementation, multiplication and division operations are implemented by the software. Because all the calculations, are executed in every switching period, the implementation of conventional methods requires a high speed digital controller [16]. Although so many digital PFC control methods were presented in the reference papers [19-21], there are still several problems that needed to be solved for digital implementations. In digital control PFC, the problems are mainly related to the following aspects: high calculation required in one switching cycle, high cost of the 
digital controller and limited switching frequency compared with analog control.

In this paper, in order to achieve higher switching frequency with low cost, low calculation requirements and better performance than the conventional PFC control methods a predictive digital PFC control is proposed. One of the significant characteristics of the proposed digital PFC control method is that the switching frequency is not directly dependent on the speed of the DSP. Therefore, a low-cost $\mathrm{DSP} /$ microprocessor could be used to control the switch operating at a high switching frequency. The effect of the PFC circuit on the magnitude of the input current, harmonic content and input power factor of the A.C. drive system will be present in this paper. In order to achieve higher switching frequency with low cost, low calculation requirements and better performance than the conventional PFC control methods a predictive digital PFC control is proposed.

Figure 1 shows a diode bridge rectifier and PFC circuit based inverter-fed induction motor drive system. The inverter is made of IGBT switches and controlled with Fieldoriented control (FOC) algorithm. The PFC circuit is controlled with the proposed predictive current control method studying in details.

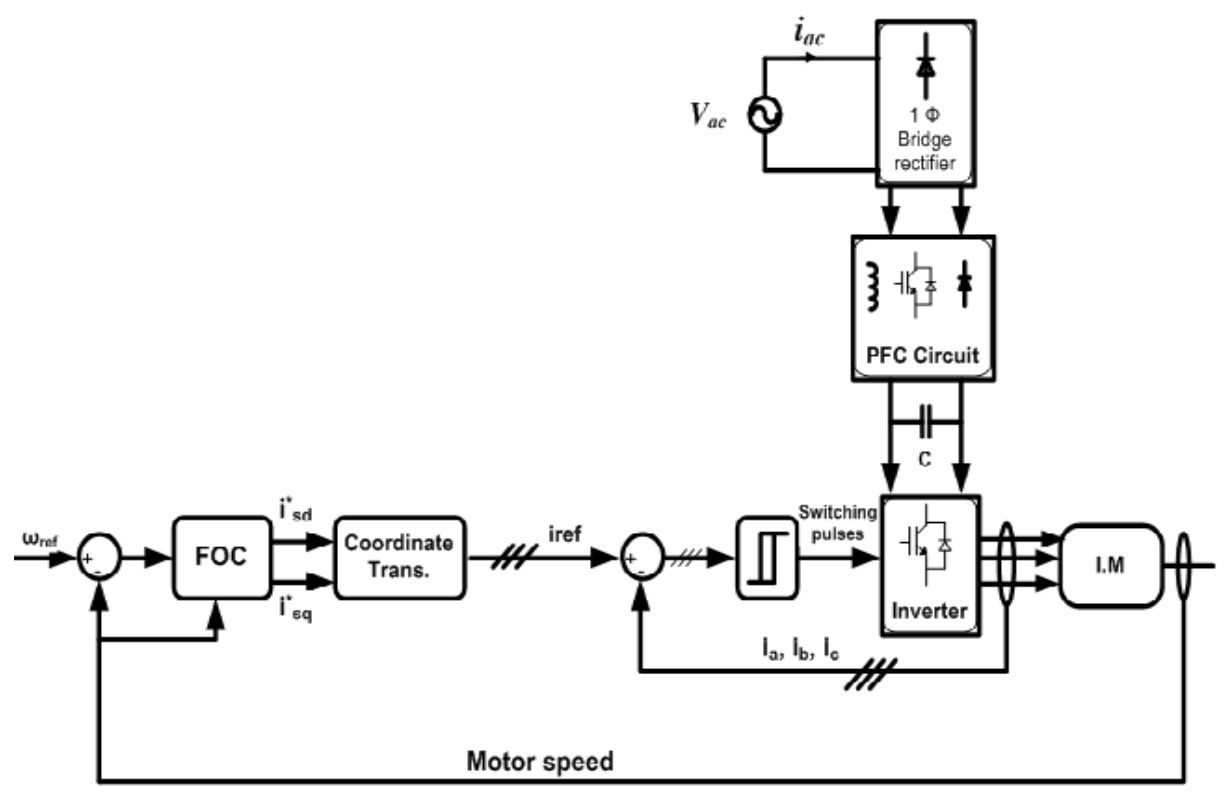

Fig. 1 Schematic diagram of the induction motor drive system with PFC circuit.

\section{Predictive Algorithm For Boost Converter:}

The block diagram of the digital controlled boost PFC based on the Predictive control algorithm is shown in Fig. 2. The duty cycles are generated by the predictive algorithm. 
The rectified voltage, $V_{i n}$, is sensed for peak value and zero cross signal detection. The peak value of the rectified voltage is used in the predictive algorithm implementation to determine the value of input voltage. The reference current, $i_{r e f(n+1)}$, is from the multiplier. Its amplitude is determined by the output of the PI controller in the voltage loop. The current sinusoidal waveform is determined by the sine wave look-up table. The output voltage, $V_{\mathrm{o}}$, is controlled by the closed loop using a PI regulator. The output of the digital control system is the gate signal for the switch, $\mathrm{S}$. The equivalent circuit of Boost converter is shown in Fig. 3a. The proposed predictive PFC algorithm is developed based on the following assumptions: Boost converter operates at continuous conduction mode $(\mathrm{CCM})$; the switching frequency is much higher than the line frequency.

When the switch is on, the inductor current, $\mathrm{i}_{\mathrm{L}}(\mathrm{t})$, can be expressed as:

$$
L \frac{d i_{L}}{d t}=V_{\text {in }}(t) \text { for } \quad t(n) \leq t<t(n)+d(n) \cdot T_{s}
$$

When the switch is off, the inductor current, $\mathrm{i}_{\mathrm{L}}(\mathrm{t})$, can be expressed as:

$L \frac{d i_{L}}{d t}=V_{i n}(t)-V_{o}(t)$ for $t(n)+d(n) \cdot T_{s} \leq t<t(n+1)$

Where $V_{\text {in }}(t)$ is the input voltage, $\operatorname{Vo}(t)$ is the output voltage, $t(n)$ and $t(n+1)$ are the beginning instant of $n^{\text {th }}$ and $(n+1)^{\text {th }}$ switching cycle, $d(n)$ is the duty cycle in the $n^{\text {th }}$ switching cycle, and $\mathrm{T}_{\mathrm{s}}$ is the switching period. Because the switching frequency is much higher than the line frequency, the differential equations (1) and (2) can be expressed as:

$L \frac{i_{L}\left(t(n)+d(n) \cdot T_{s}\right)-i_{L}(t(n))}{d(n) \cdot T_{s}}=V_{i n}(t(n))$

$L \frac{i_{L}(t(n+1))-i_{L}\left(t(n)+d(n) \cdot T_{s}\right)}{[1-d(n)] \cdot T_{s}}=V_{i n}(t(n))-V_{o}(t(n))$

Where $i_{L}[t(n)], i_{L}[t(n+1)]$ are the inductor current at the beginning of $n^{\text {th }}$ and $(n+1)^{\text {th }}$ switching cycles. The inductor current in one switching cycle is shown in Fig. 3c.

The inductor current at the switching off instant, $t(n)+d(n) T_{s}$, can be derived from equation (3):

$i_{L}\left(t(n)+d(n) \cdot T_{s}\right)=i_{L}(t(n))+\frac{1}{L} \cdot V_{i n}(t(n)) \cdot d(n) \cdot T_{s}$

The inductor current at the beginning instant of $(n+1)^{\text {th }}$ switching cycle,$t(n+1)$, can be derived from equation (4) as:

$i_{L}(t(n+1))=i_{L}\left(t(n)+d(n) \cdot T_{s}\right)+\frac{1}{L} \cdot\left(V_{i n}(t(n))-V_{o}(t(n)) \cdot(1-d(n)) \cdot T_{s}\right.$ 
Substituting equations (5) and (6), the inductor current at the beginning instant of $(n+1)^{\text {th }}$ switching cycle in terms of the inductor current at the beginning instant of $n$th switching cycle can be derived as:

$i_{L}\left(t(n+1)=i_{L}(t(n))+\frac{1}{L} \cdot V_{i n}(t(n)) \cdot T_{s}-\frac{1}{L} V_{o}(t(n)) \cdot(1-d(n)) \cdot T_{s}\right.$

The discrete form of equation (3-8) can be expressed as:

$i_{L}(n+1)=i_{L}(n)+\frac{V_{i n}(n) \cdot T_{s}}{L}-\frac{V_{o}(n) \cdot(1-d(n)) \cdot T_{s}}{L}$

The above equation indicates that the inductor current at the beginning of the next switching cycle is determined by the inductor current at the beginning of the present switching cycle, the input voltage, the output voltage and the duty cycle for the present switching cycle.

Equation (8) can be rewritten as

$d(n)=\frac{L}{T_{S}} \frac{i_{L}(n+1)-i_{L}(n)}{V_{o}}+\frac{V_{o}(n)-V_{i n}(n)}{V_{o}}$

It is observed that the required duty cycle for the present switching cycle, $d(n)$, can be determined based on the boost circuit parameters, the output voltage, the input voltage and the required inductor current. In a properly designed AC-DC converter with PFC, $\mathrm{i}_{\mathrm{L}}(\mathrm{n}+1)$, is forced to follow the reference current, $\mathrm{i}_{\text {ref }}(\mathrm{n}+1)$, which is a rectified sinusoidal waveform. $V_{o}$, is controlled to follow the reference voltage, $V_{\text {ref. }}$. Substituting $\mathrm{i}_{\text {ref }}(\mathrm{n}+1), V_{\text {ref }}$ for $\mathrm{i}_{\mathrm{L}}(\mathrm{n}+1)$ and $V_{o}$ respectively in equation (9), the duty cycle can be derived as:

$d(n)=\frac{L}{T_{S}}\left(\frac{i_{r e f}(n+1)-i_{L}(n)}{V_{r e f}}\right)+\frac{V_{r e f}-V_{i n}(n)}{V_{r e f}}$

The reference current, $\mathrm{i}_{\text {ref }}$ is determined as:

$\mathrm{i}_{\text {ref }}(\mathrm{n}+1)=\mathrm{K}_{\mathrm{PI}} . \mid \sin \left(\omega_{\text {line. }} \mathrm{t}(\mathrm{n}+1) \mid\right.$

$\mathrm{K}_{\mathrm{PI}}$ is the peak value of reference current, which is the output of the voltage loop controller, $\sin \left(\omega_{\text {line. }} . \mathrm{t}(\mathrm{n}+1)\right.$ (is the rectified sinusoidal waveform), it can be determined from a look-up table in digital implementation or a resistor divider from the rectified input voltage. The predictive algorithm given by equation (10) can be used to generate the duty cycles and achieve unity power factor with Boost converter in the digital implementation. 


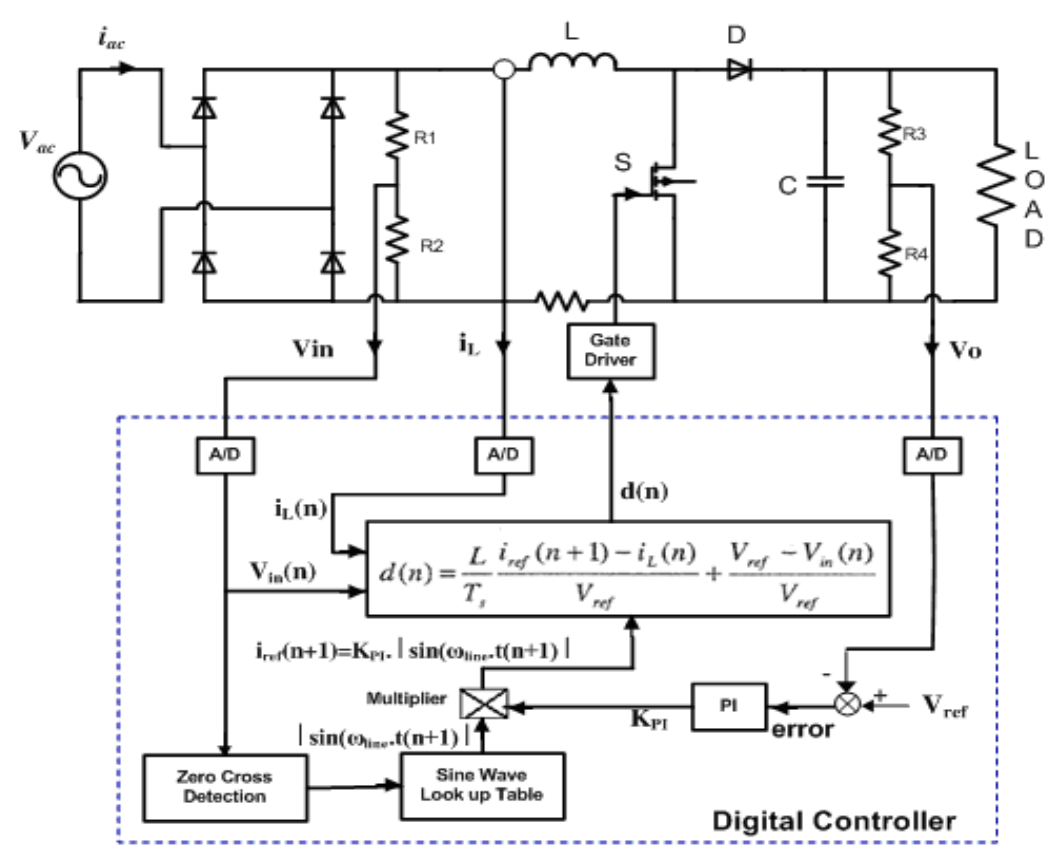

Fig. 2 Digital implementation of proposed Predictive control

Therefore, the input voltage, $V_{\text {in }}$, and output voltage, $V o$, can be assumed as constant during one switching cycle, Ts. Thus, when the switch $\mathrm{S}$ is on or off, the boost converter is described by two modes of operation, as shown in Fig. $3 b$.

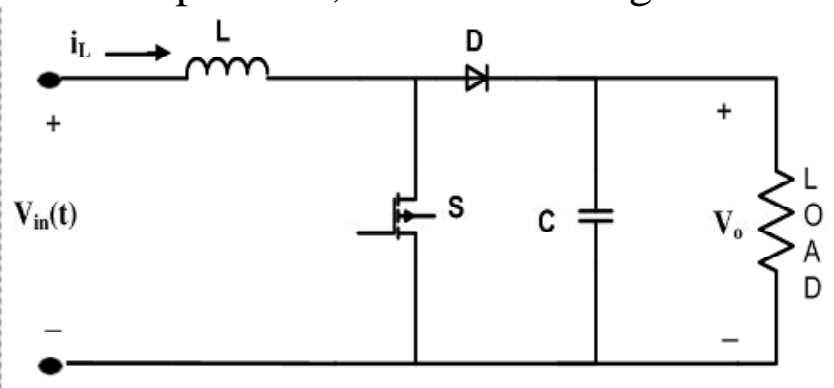

(a)

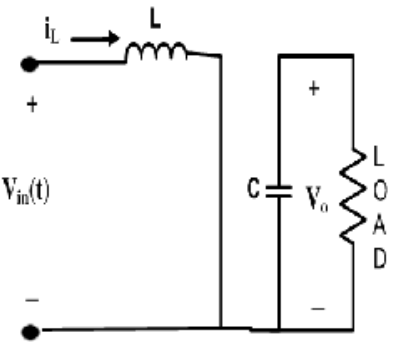

(a) Mode 1

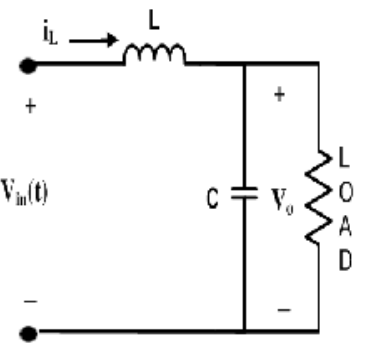

(b) Mode 2

(b) 


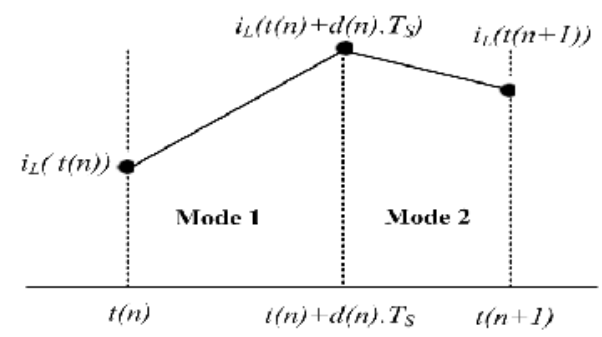

(c)

Fig. 3. (a) Equivalent circuit of boost converter (b) Boost converter equivalent circuits (c) Inductor current in one switching cycle

\section{Simulation Results}

It is usual practice to simulate the drive system on the computer and predict the performance before real-time implementation. The simulation of the proposed complete drive system has been carried out using MATLAB SIMULINK software. The simulation allows investigation of both transient and steady-state performance of the drive system. The simulation results of a.c drive system with PFC are taken with the following specifications: ac input voltage, $220 \mathrm{~V}$; dc output voltage, $400 \mathrm{~V}$; line frequency (f), $50 \mathrm{~Hz}$; inductor (L), $10 \mathrm{mH}$ and dc link capacitor (C), $6600 \mu \mathrm{F}$. The motor parameters of the system are reported in appendix (A).

\section{A. Starting and Steady-State Operations}

The results are taken at load torque 7 N.m and $100 \mathrm{rad} / \mathrm{sec}$ speed command for ac drive system with and without PFC circuit. The supply current waveforms and its corresponding total harmonic distortion at run-up and steady-state, for ac drive system without and with PFC are shown in Figs. 4 and 5 respectively. As seen from these figures, the steady-state input current for ac drive system with PFC has a smaller peak value and smaller RMS value ( $\mathrm{I}_{\mathrm{i}}$ (r.m.s)) than supply current for ac drive system without PFC as shown in Fig.4. Figure 5a shows the total harmonic distortion (THD) for ac drive system without PFC. Moreover, the ac drive system with PFC has smaller harmonic contents in supply current and high PF as shown in figure Fig.5b. 


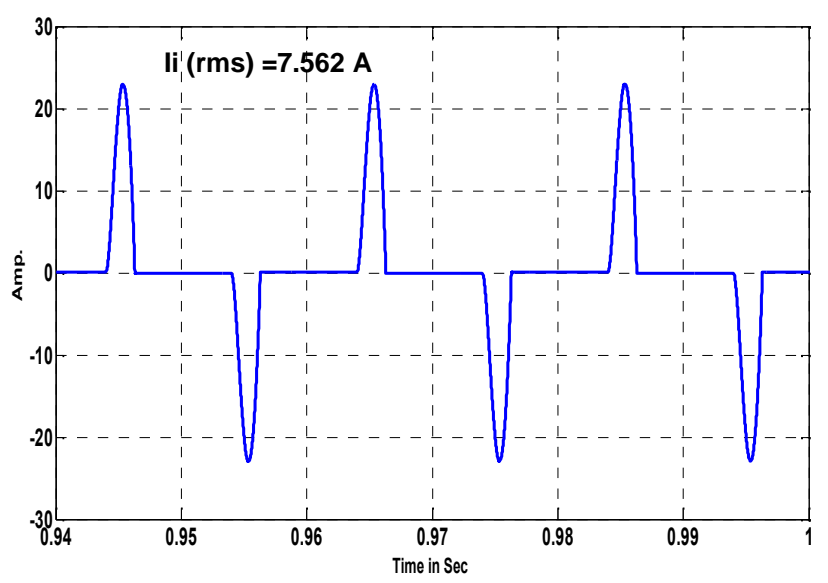

(a)

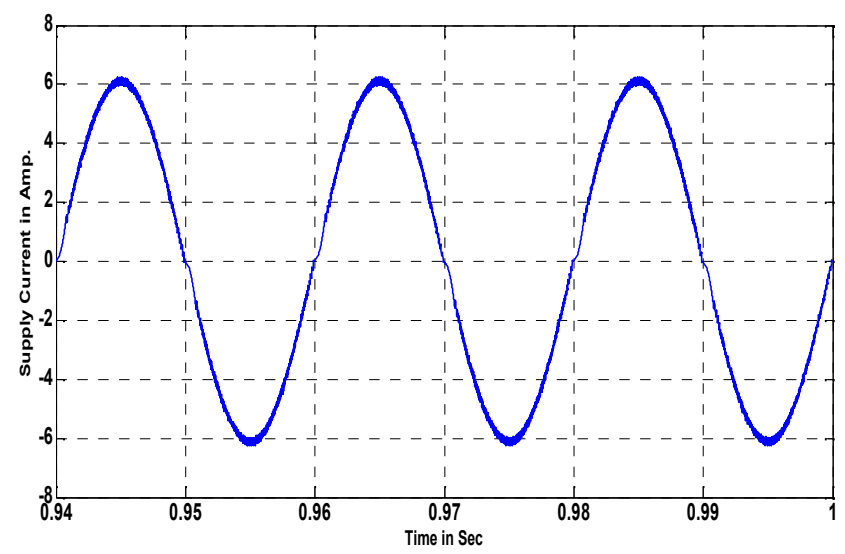

(b)

Fig. 4. (a) Supply current waveform at steady-state without PFC (b) Supply current waveform at steady-state with PFC

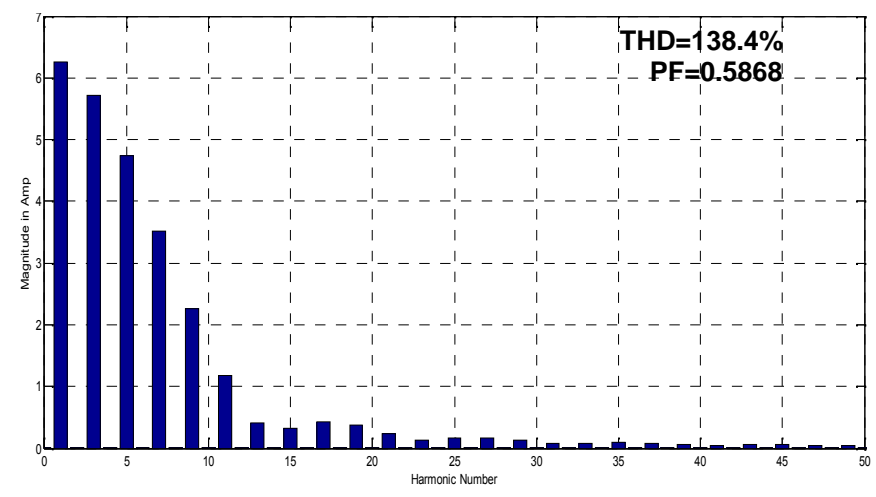

(a) 


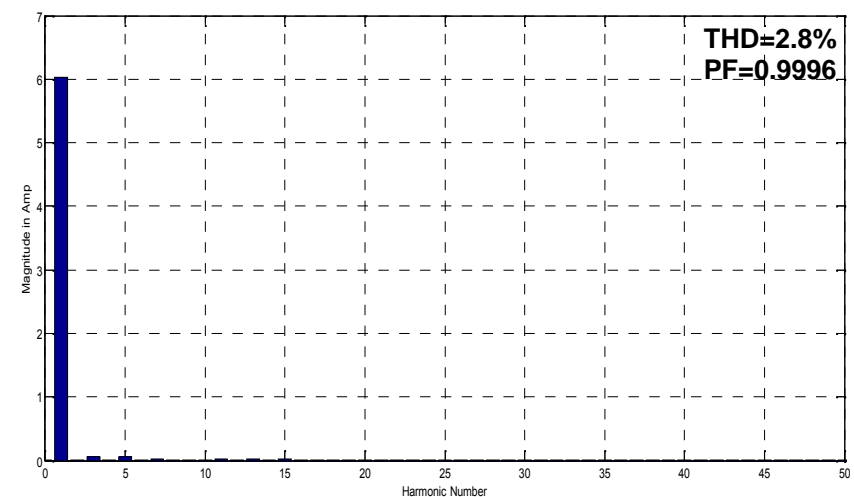

(b)

Fig. 5. (a) Supply current THD without PFC (b) Supply current THD without PFC

Figure 6 shows the supply voltage $\left(\mathrm{v}_{S}\right)$ and supply current $\left(\mathrm{i}_{S}\right)$ waveforms for ac drive system without and with PFC respectively. As seen from these figures, there is a voltage dip in the input voltage for the system without PFC as shown in Fig.6a. The input current for ac drive system with PFC is sinusoidal and in phase with voltage as shown in Fig.6b.

The rectified current $\left(i_{R}\right)$ and reference current $\left(i_{\text {ref }}\right)$ under the steady state for ac drive system with PFC are shown in Fig. 7. It is clear that, the rectified current is very close to reference current.

Figure 8, shows the output converter voltage for ac drive system without and with PFC respectively. As seen from these figures, the output voltage for drive system with $\mathrm{PFC}$ is constant during run-up and gives minimum voltage ripple than ac drive system without PFC.

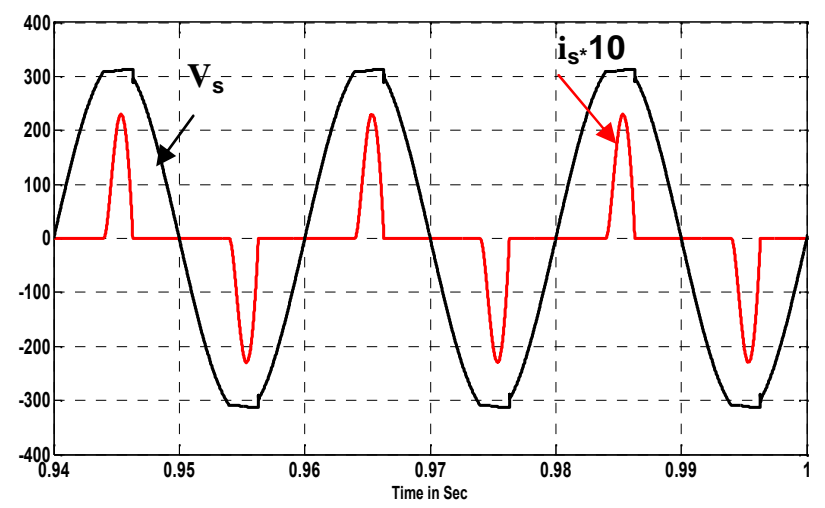

(a) 


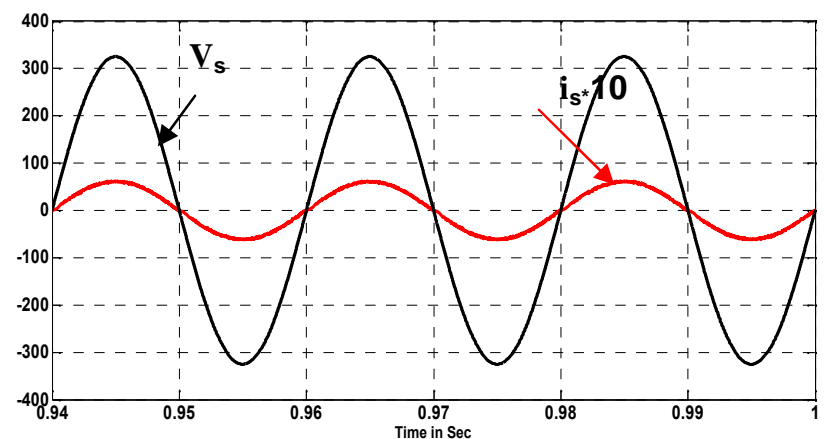

(b)

Fig. 6.(a) Input voltage and current Waveforms without PFC (b) Input voltage and current waveforms with PFC

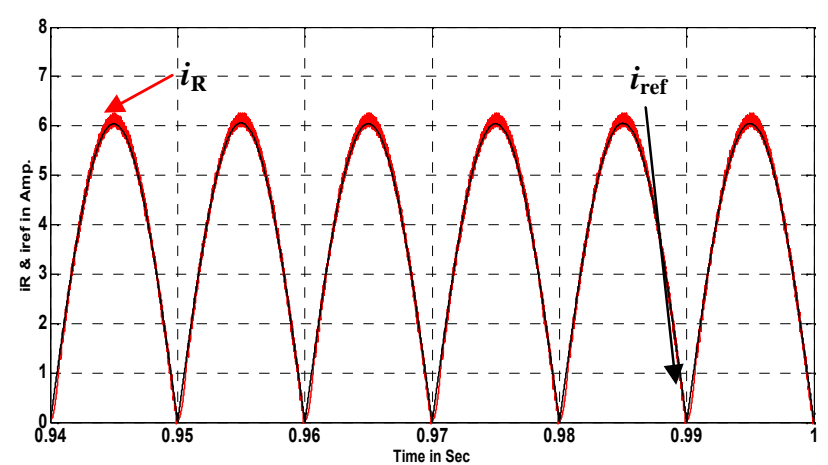

Fig. 7. Rectified current and reference current for ac drive system with PFC

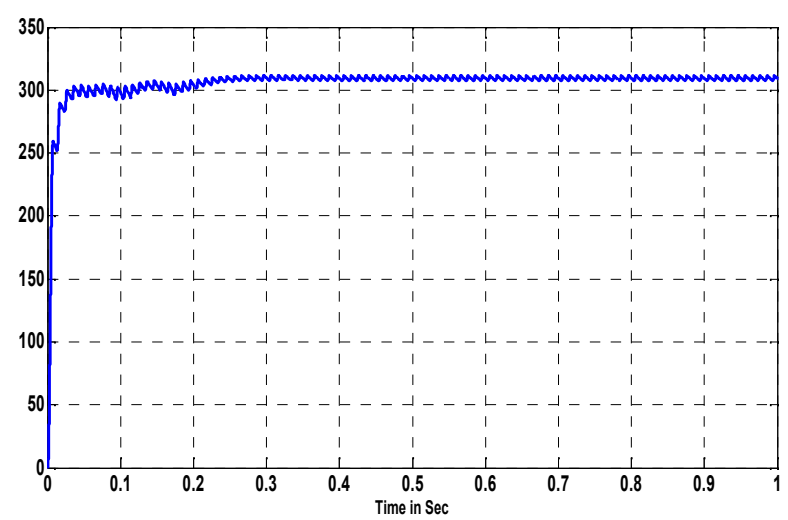

(a) 


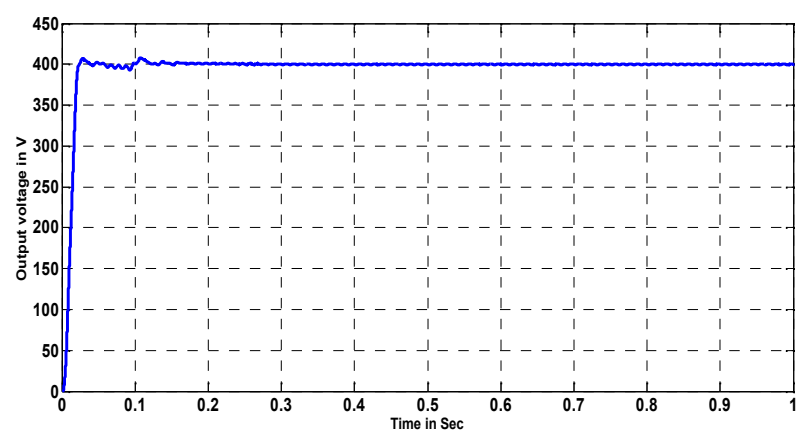

(b)

Fig. 8. Output voltage (a) without PFC (b) with PFC

Figure 9 shows three-phase motor currents at run-up and steady-state for ac drive system without and with PFC. As seen from these figures, the three-phase motor currents for ac drive system with PFC takes a short time to reach steady-state value than the system without PFC as shown in Figs. 9a and 9b. Also, the current ripple for ac drive system with PFC is less than the system without PFC.

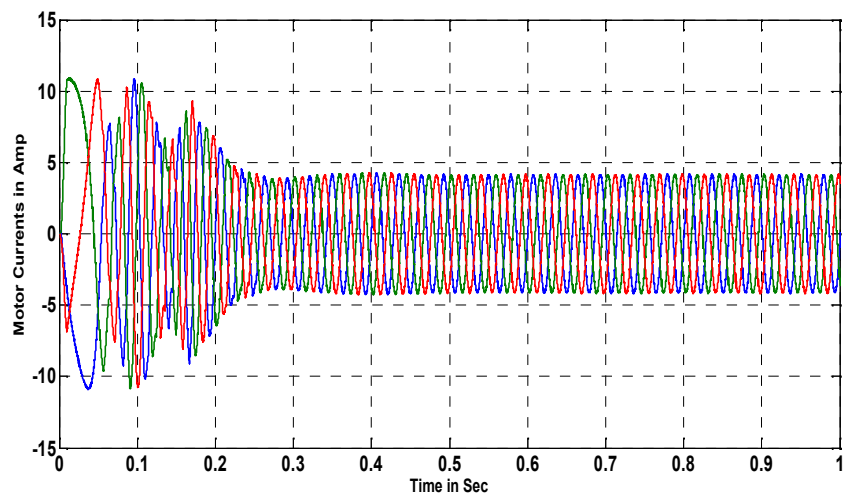

(a)

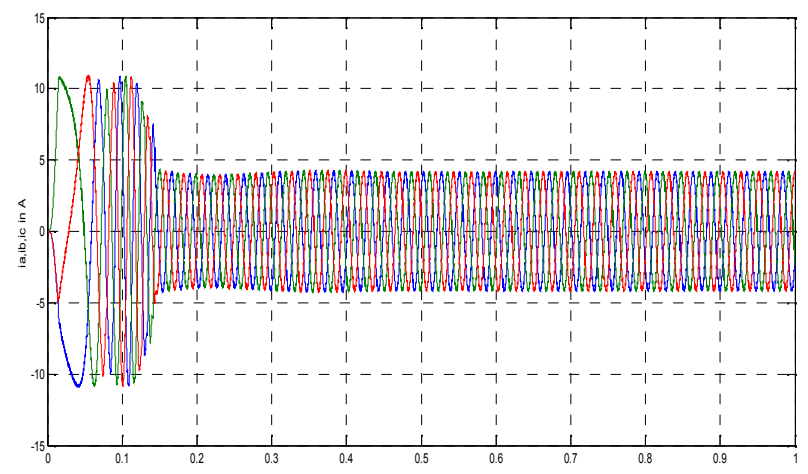

(b)

Fig. 9. Motor currents during run-up (a) without PFC (b) with PFC 
The motor speed during run-up for ac drive system without and with PFC is shown in Figs. 10a and 10b. It is noticed that, the motor speed for ac drive system with PFC takes a short time to reach steady-state value than the system without PFC. Figures $10 \mathrm{c}$ to $10 \mathrm{~d}$, show the motor torque at run-up and steady-state for ac drive system without and with PFC respectively. It is observed that, the motor torque for ac drive system with PFC takes a short time to reach-steady state value than the system without PFC.

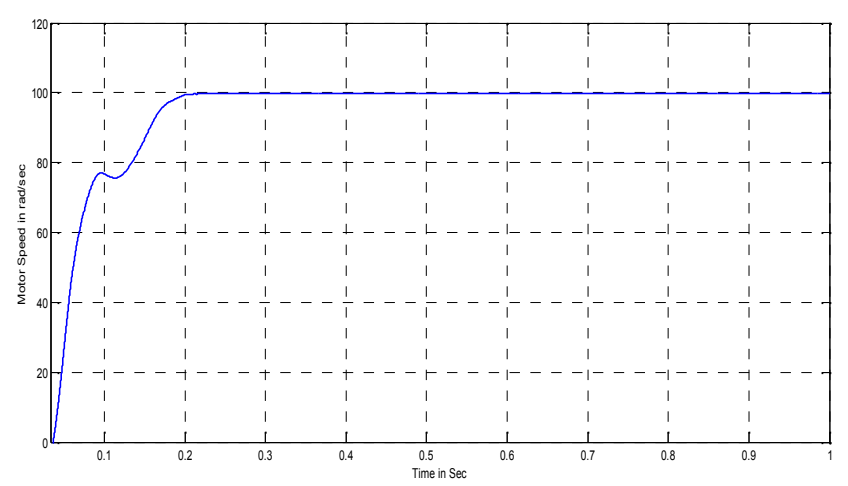

(a)

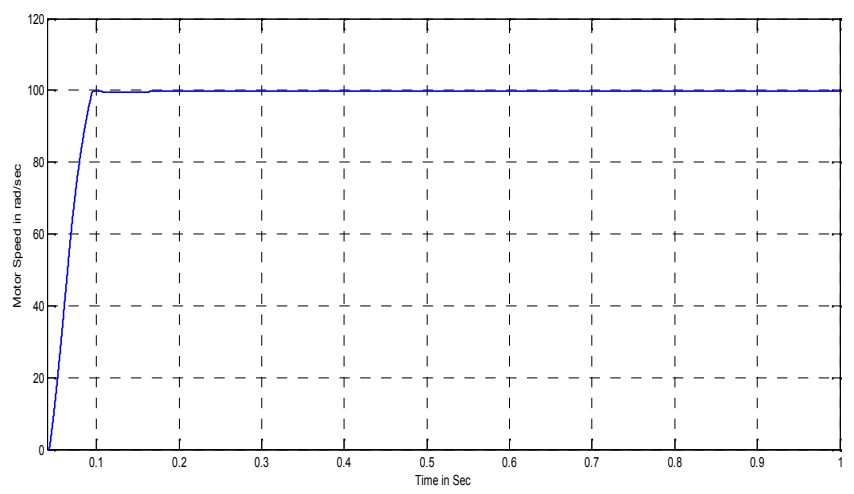

(b)

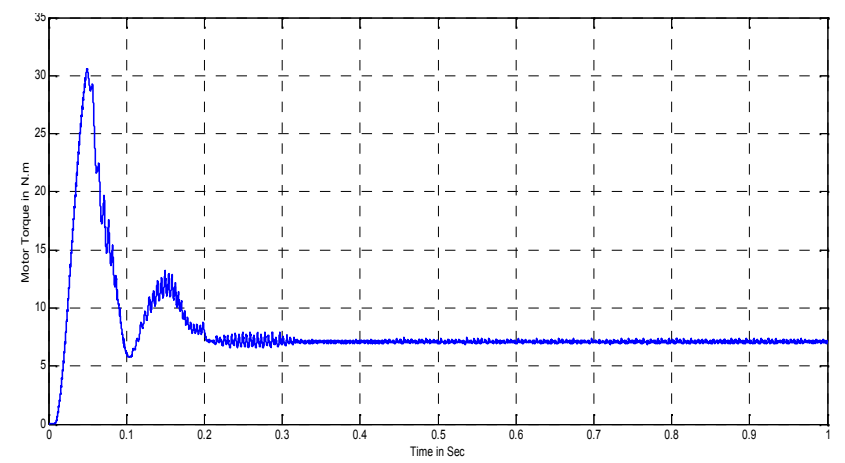

(c) 


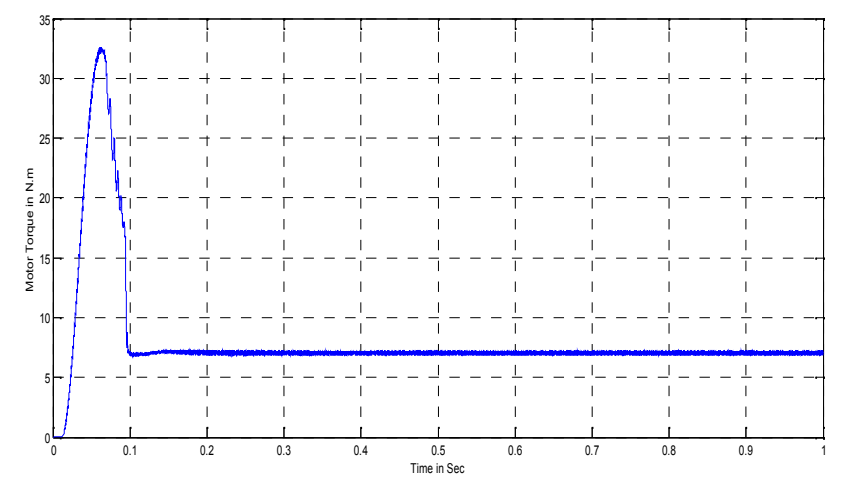

(d)

Fig. 10. (a) Motor speed without PFC during run-up (b) Motor speed with PFC during run-up (c) Motor torque without PFC during run-up (d) Motor torque with PFC during run-up

\section{B. Positive and Negative Step Change in Load Torque (from 4:7:4 N.m at w=100 $\mathrm{rad} / \mathrm{sec}$ )}

One important property of a high performance drive is its robustness to the disturbance like change of load and speed step up and speed step down which are very common types of disturbances. Therefore, this property is tested.

Figure 11 shows supply current waveforms due Positive and negative step change in load torque, for ac drive system without and with PFC respectively. It is observed that, the supply current follows the load torque in its increasing and decreasing. Figures 12a and $12 \mathrm{~b}$, show the output voltage due to Positive and negative step change in load torque, for ac drive system without and with PFC respectively. As seen from these figures, the output voltage for drive system without PFC is decreases when increasing the load torque and increases when decreasing the load torque. The output voltage for drive system with PFC is constant during step change in load torque and gives minimum voltage ripple than ac drive system without PFC. Figures 13a and 13b, shows motor torque for ac drive system without and with PFC respectively. As seen from these figures, the motor torque follows load torque.

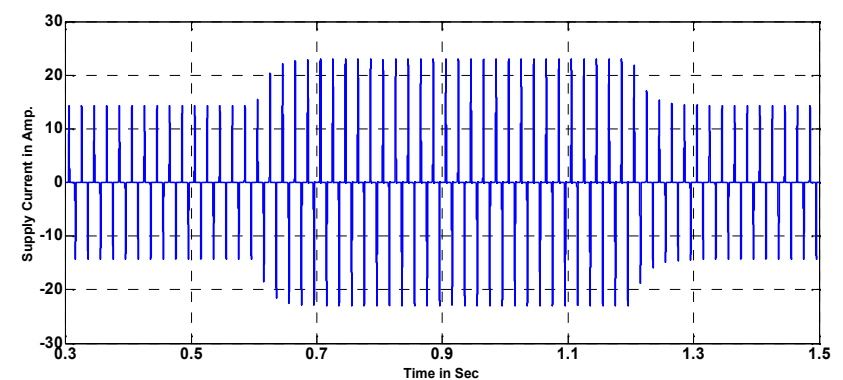

(a) 


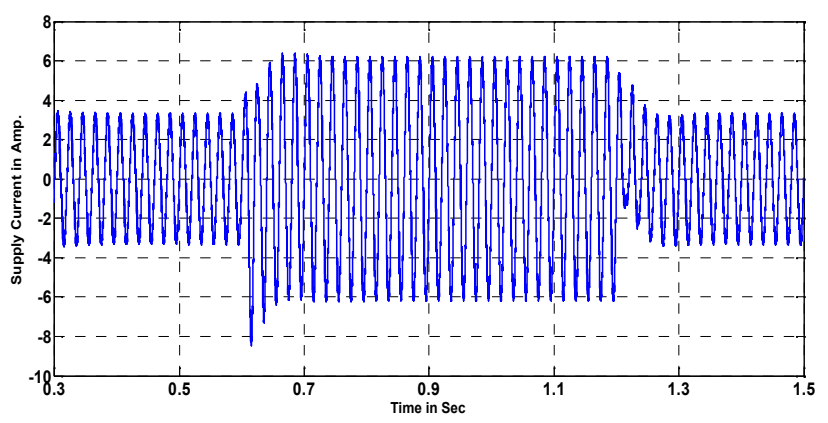

(b)

Fig. 11. Supply current waveform due to positive and negative step change in the load (a) without PFC (b) ) with PFC

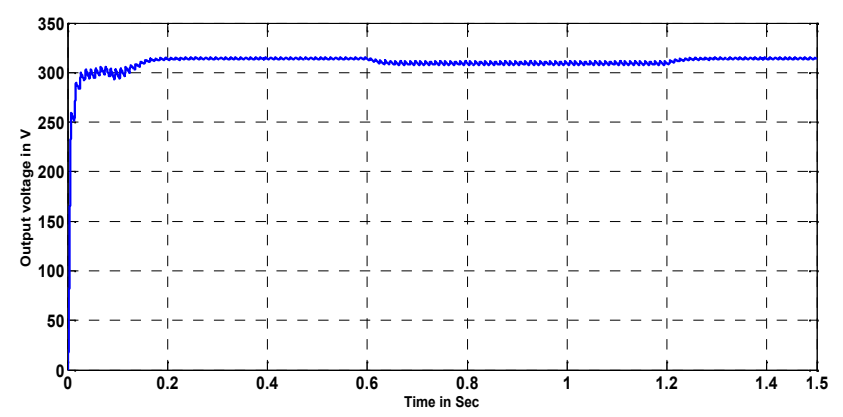

(a)

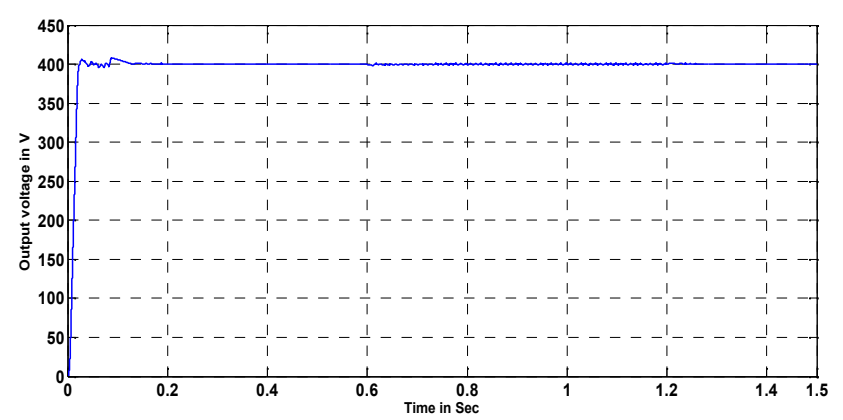

(b)

Fig. 12. Output voltage due to positive and negative step change in the load torque (a) without PFC (b) ) with PFC 


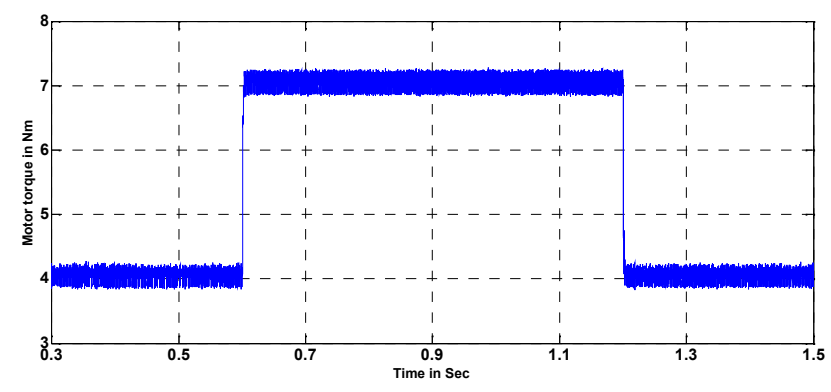

(a)

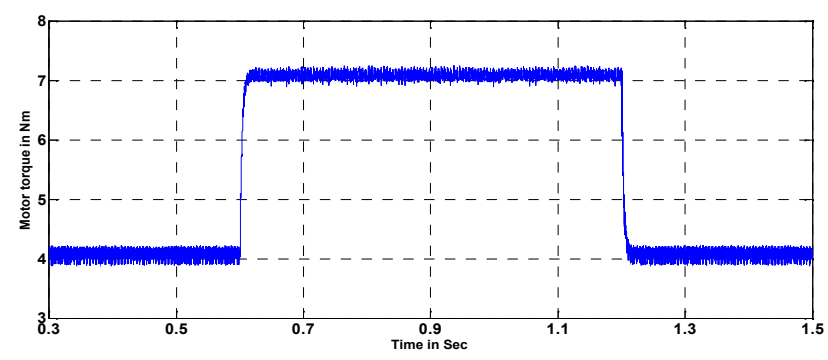

(b)

Fig. 13. Motor torque due to positive and negative step change in the load torque (a) without PFC (b) ) with PFC

\section{Positive and Negative Step Change in Reference Speed (from70:100:70 rad/sec at $T_{L}=5$ N.m)}

Figures 14a and 14b show supply current waveforms due Positive and negative step change in reference speed for ac drive system without and with PFC respectively. It is observed that, the supply current follows the reference speed in its increasing and decreasing. Also, the input current for ac drive system with PFC takes a short time to reach steady-state value than the system without PFC. Figures $15 \mathrm{a}$ and $15 \mathrm{~b}$ show the output voltage due to Positive and negative step change in the reference speed for ac drive system without and with PFC respectively. It is noticed that, the output voltage for drive system without PFC is decreases when increasing the reference speed and increases when decreasing the reference speed. The output voltage for drive system with PFC is constant during step change in the reference speed and gives minimum voltage ripple than ac drive system without PFC. Figures 16a and 16b show three-phase motor currents due to Positive and negative step change in reference speed for ac drive system without and with PFC respectively. It is observed that, the three-phase motor currents for ac drive system with PFC takes a short time to reach steady-state value than the system without PFC. The motor speed during Positive and negative step change in reference speed for ac drive system without and with PFC is shown in figure 17. It is 
clear that, the motor speed follows the desired speed reference in its increasing and decreasing. The motor speed for ac drive system with PFC takes a short time to reach steady-state value than the system without PFC.

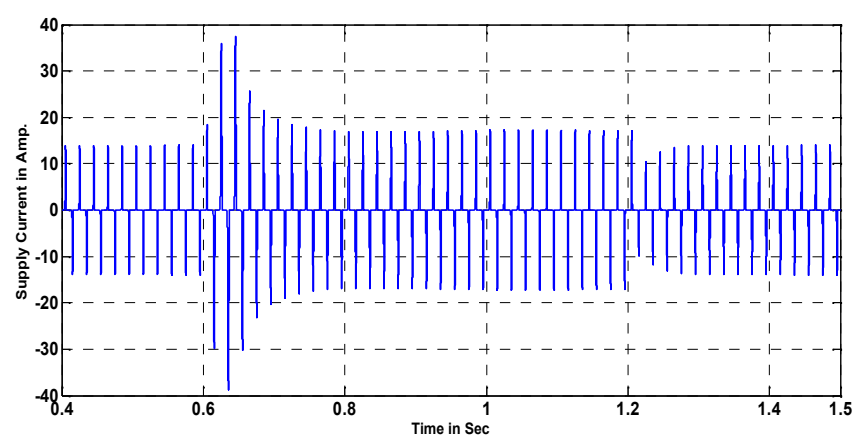

(a)

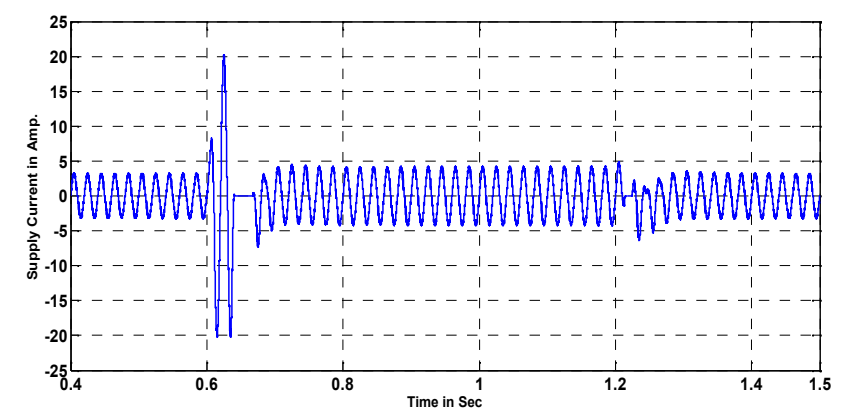

(b)

Fig. 14. Supply current waveform due to positive and negative step change in reference speed (a) without PFC (b) ) with PFC

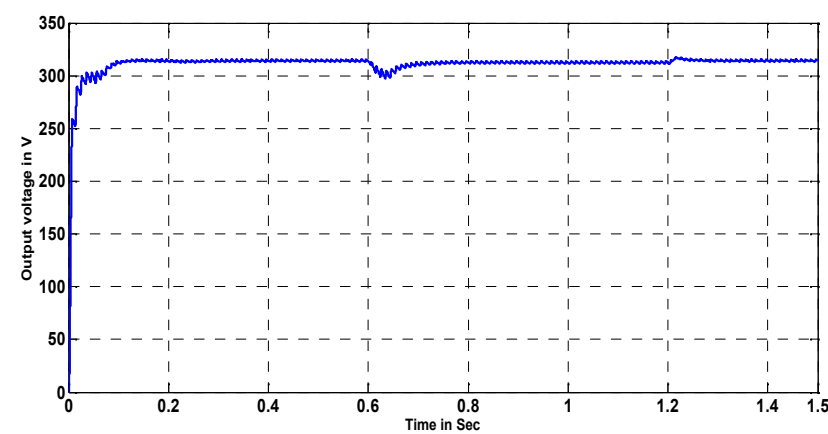

(a) 


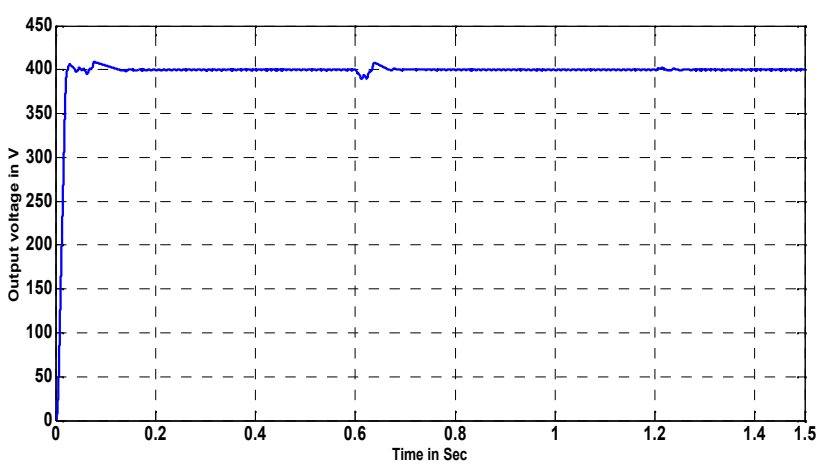

(b)

Fig. 15. Output voltage due to positive and negative step change in reference speed (a) without PFC (b) ) with PFC

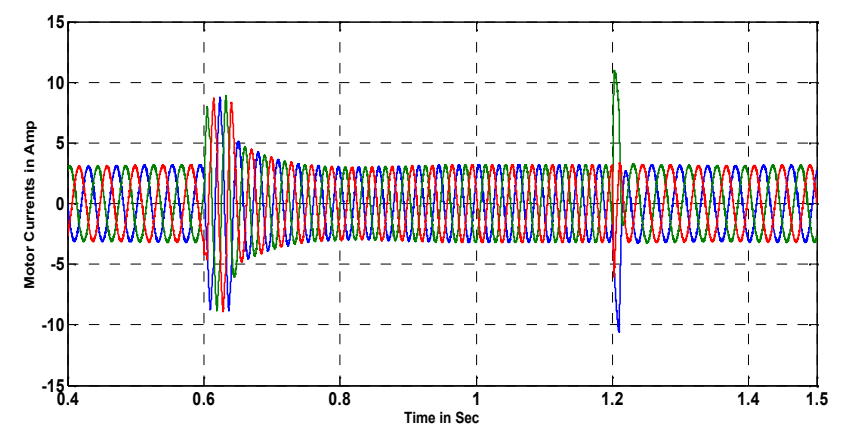

(a)

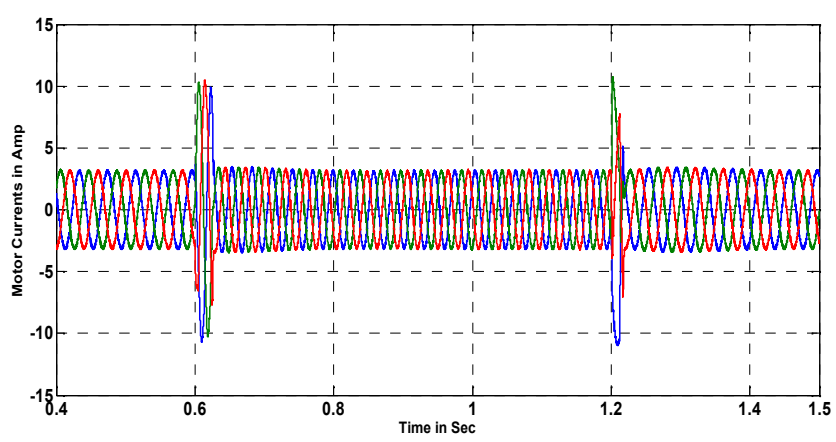

(b)

Fig. 16. Motor currents due to positive and negative step change in reference speed (a) without PFC (b) ) with PFC 


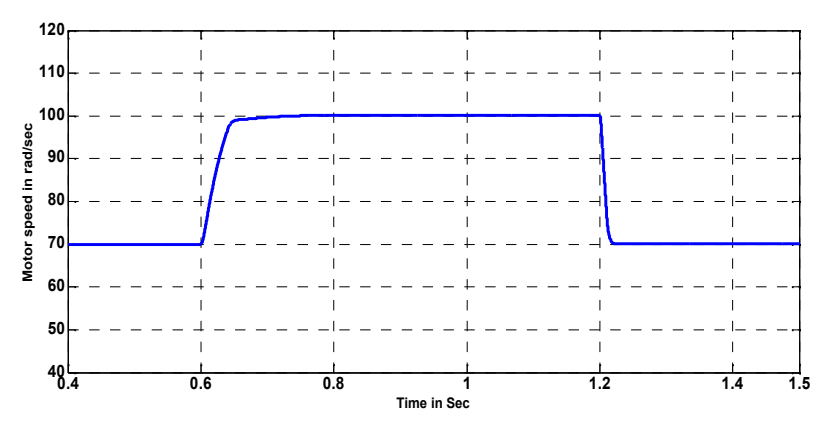

(a)

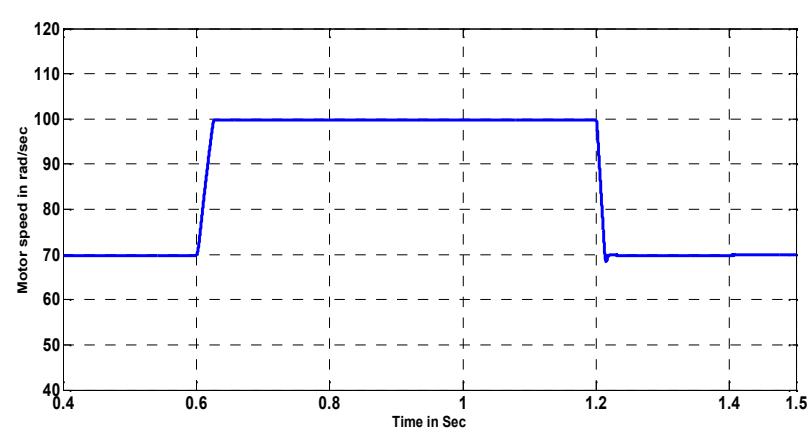

(b)

Fig. 17. Motor speed due to positive and negative step change in the load torque (a) without PFC (b) ) with PFC

\section{Experimental Results}

The experimental implementation of PFC control of the boost converter controlled three-phase IM drive system, with FOC principles in real time, using DSP controller board DS1104 is achieved using the proposed predictive control method.

Figure 18a shows the block diagram of the experimental setup of PFC control for a.c drive system. A Photograph for experimental setup of a.c drive system with PFC circuit shows in Fig.18b. The Input current waveforms and its corresponding harmonics spectrum at steady state for ac drive system without and with PFC are shown in Figs. 19 and 20 respectively. As seen from these figures, the input current for the ac drive system with PFC has a smaller peak value, smaller harmonic contents than input current for ac drive system without PFC. Figure 21 shows the supply voltage and current for ac drive system without and with PFC respectively. As seen from these figures, there is a voltage dip in the supply voltage for the system without PFC as shown in Fig. 21a. The supply current for ac drive system with PFC is nearly sinusoidal and in phase with voltage as shown in Fig. 21b. The reference current, rectified current and the voltage error for ac 
drive system with PFC are shown in figure 22. It is clear that, the rectified current is very close to reference current and steady state voltage error is zero.

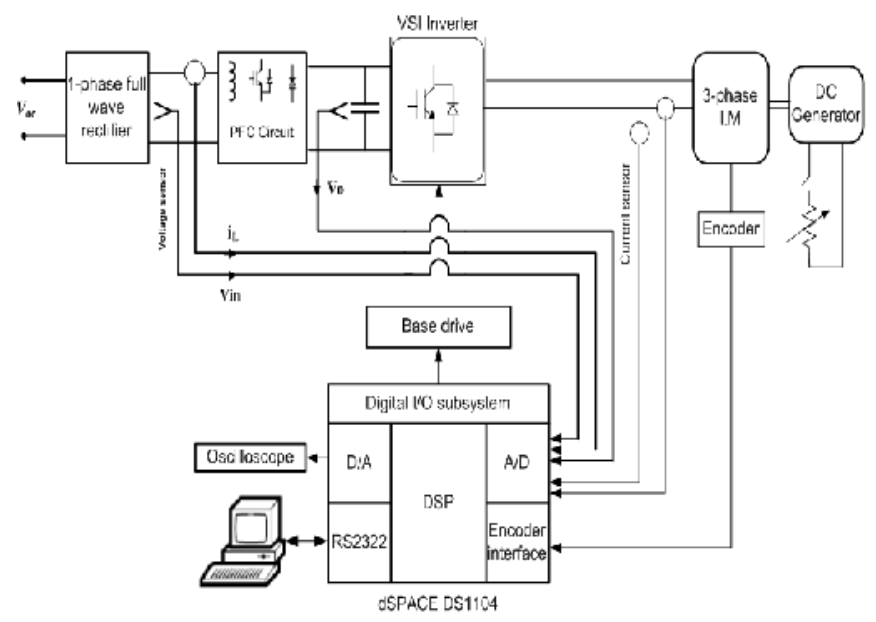

(a)

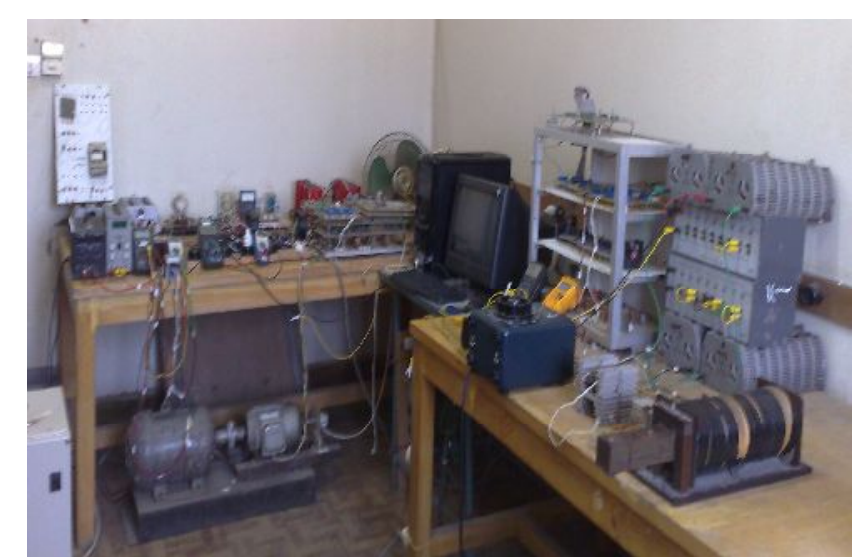

(b)

Fig. 18. (a) Hardware schematic diagram for the experimental implementation of PFC for ac drive system (b) Experimental setup for the a.c drive system with PFC circuit

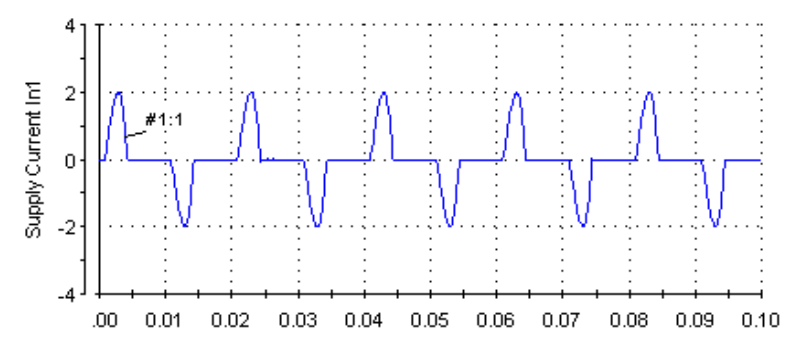

— $1: 1 \ln 1$ (Model Root'Supply Current/In1)

(a) 


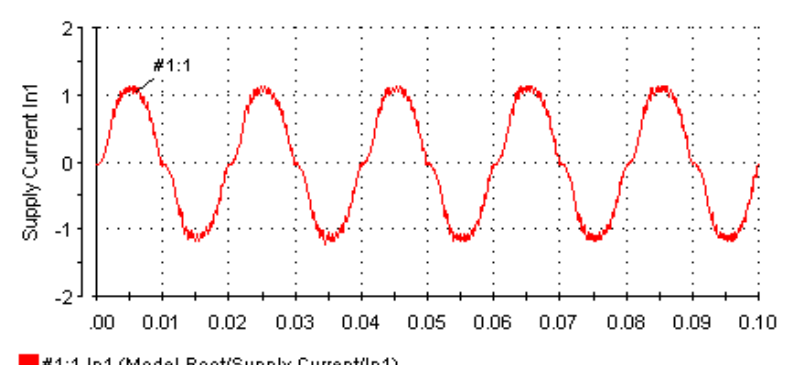

(b)

Fig. 19. Supply current waveform at steady-state (a) without PFC (b) with PFC

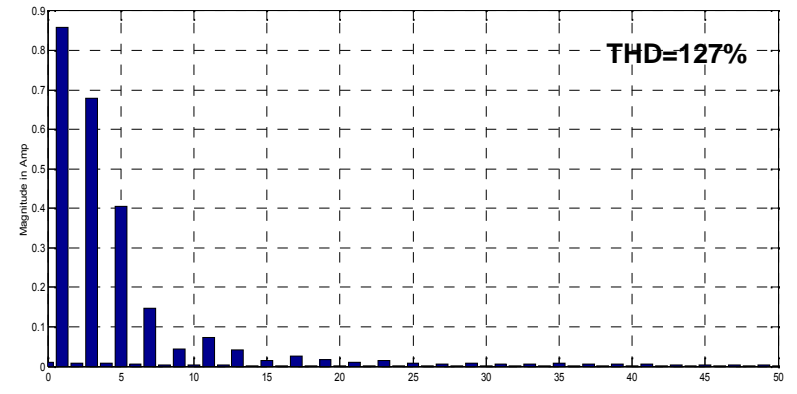

(a)

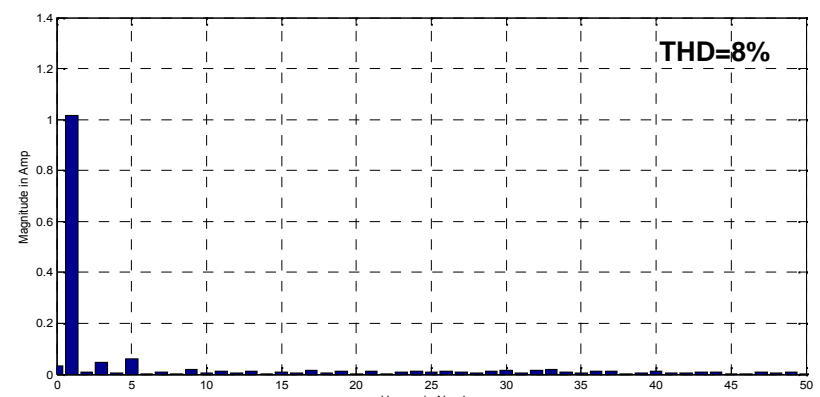

(b)

Fig.20 Harmonics spectrum of supply current (a) without PFC (b) with PFC

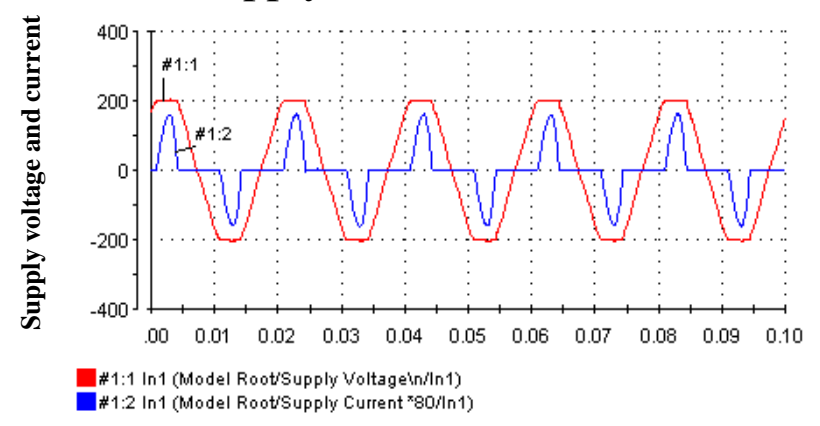

(a) 


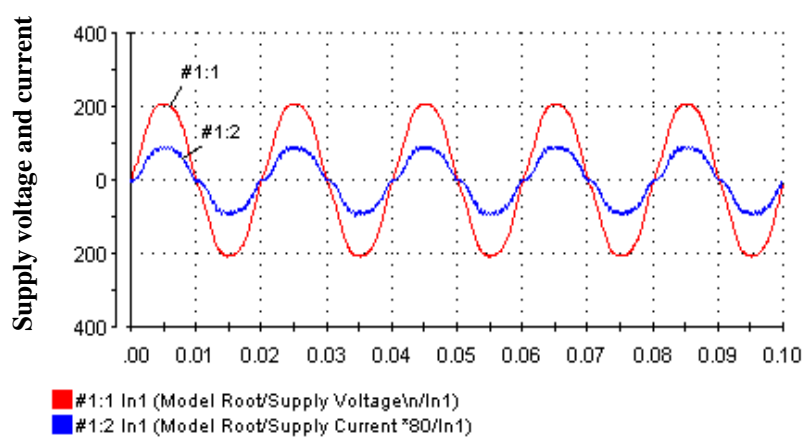

(b)

Fig.21. Supply voltage and current waveforms (a) without PFC (b) with PFC

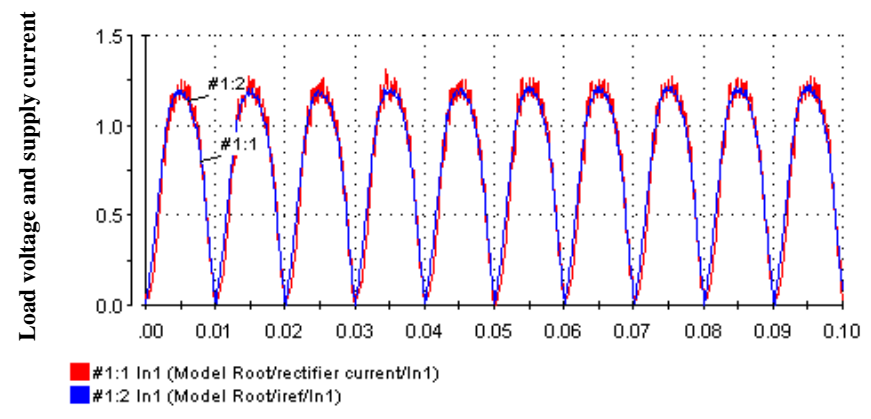

(a)

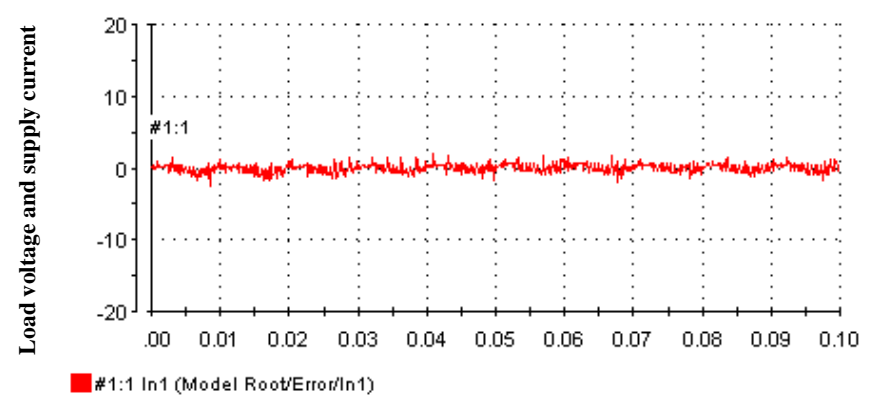

(b)

Fig.22. (a) Rectified current and reference current for ac drive system with PFC (b) Voltage error for ac drive system with PFC

Figure 23 show input current waveforms due Positive change in load torque from no load to $7 \mathrm{~N} . \mathrm{m}$ at $100 \mathrm{rad} / \mathrm{sec}$ speed command, for ac drive system without and with PFC respectively. It is observed that, the supply current follows the load torque in its increasing. Load voltage and supply current due to Positive change in load torque for ac drive system without and with PFC are shown in Fig 24. 


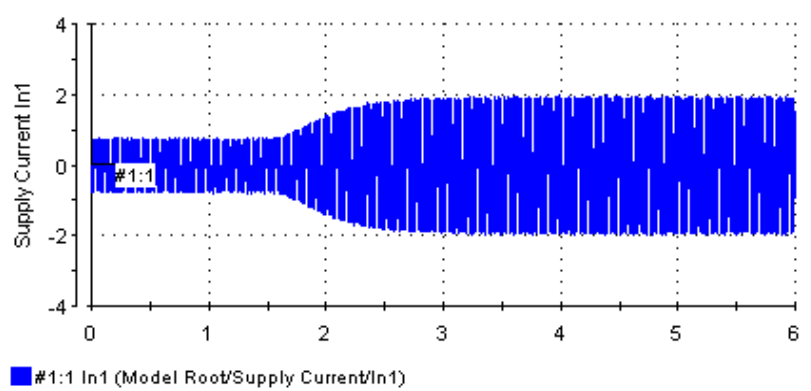

(a)

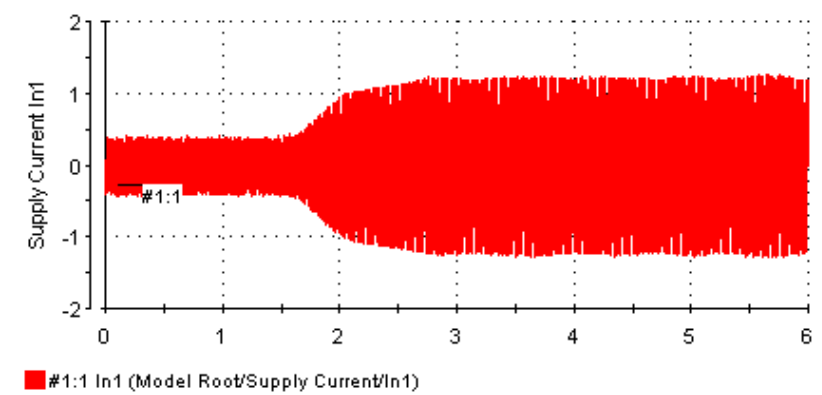

(b)

Fig.23. Supply current waveform due to positive change in the load torque (a) without PFC (b) with PFC

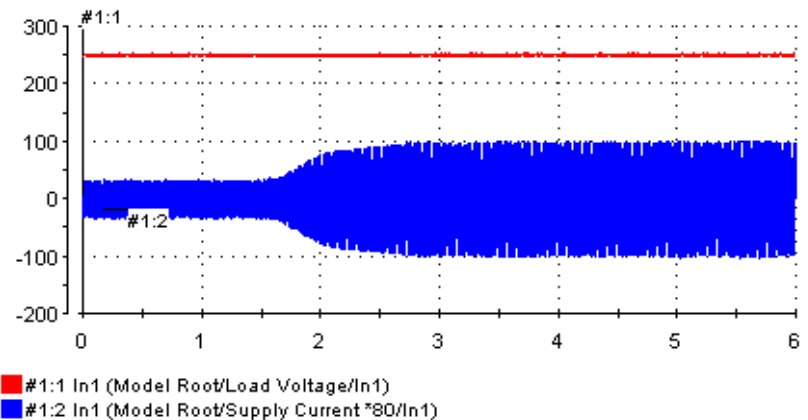

(a)

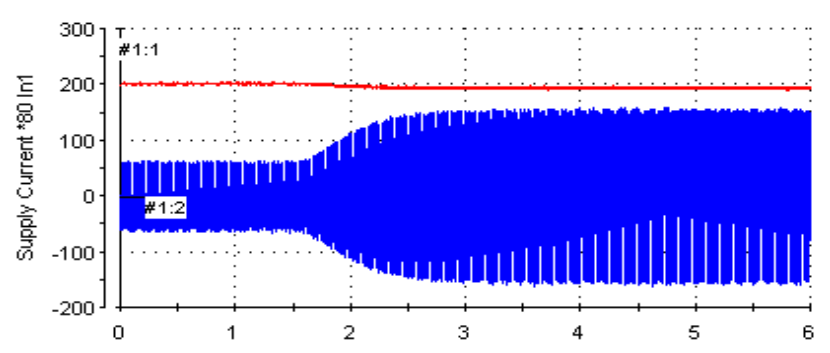

E $1: 1 \ln 1$ (Model Root/Load Voltage/ln1)

\#1:2 In1 (Model Root/Supply Current ${ }^{*} 80 / \ln 1$ ) 
(b)

Fig.24. Load voltage and supply current due to positive change in the load torque (a) without PFC (b) with PFC

\section{Conclusions:}

Power factor correction integrated with three-phase inverter-fed induction motor drive with single phase utility input has been presented in this paper. The PFC circuit of this system is controlled with the proposed predictive current control. The effects of the PFC circuit on the magnitude of the input current, harmonic contents and input power factor of the a.c drive system have been studied. A comparison has been made among the ac drive system with and without PFC circuit based on simulation results in both transient and steady-state operations. It is found that from these results, The input current for ac drive system with PFC takes a short time for reach steady-state value than the system without PFC. The steady state input current for ac drive system with PFC has a smaller peak value and smaller RMS value than input current for ac drive system without PFC. Moreover, the ac drive system with PFC has smaller harmonic contents in input current and high PF. The input PFC circuit draws a nearly sinusoidal current, from an ac source, in phase with voltage for ac drive system with PFC. The a.c drive system performance in both transient and steady-state operations with the power factor correction circuit is better than without PFC. It provides constant DC-link voltage during transient and steady state conditions.

\section{References:}

[1] Supratim Basu and Math.H.J.Bollen, "A Novel Common Power Factor Correction Scheme for Homes and Offices," IEEE Transactions on Power Delivery, Vol.20, No.3, pp. 2257-2263, July 2005.

[2] D. Giaouris, S. Banerjee, B. Zahawi and V. Pickert, "Control of Fast Scale Bifurcations in Power-Factor Correction Converters," IEEE Transactions on Circuits and Systems, II: Express Briefs, Vol. 54, No. 9, pp. 805-809, September 2007.

[3] O. García, J. A. Cobos, R. Prieto, P. Alou and J. Uceda, "Single Phase Power Factor Correction: A survey," IEEE Transactions Power Electronronics., vol. 18, No. 3, pp. 749-755, May 2003.

[4] L.Roggia, J.E Baggio and J.R.Pinheiro, "Comparison among Digital Current Controllers applied to Power Factor Correction Boost Converters," IEEE on Energy Conversion Congress and Exposition, ECCE 2009, pp. 2965 - 2971, 2009.

[5] F. J. Azcondo, A. Castro, V. M. Lopez and O. Garcia, "Power Factor Correction Without Current Sensor Based on Digital Current Rebuilding," IEEE Trans. on Power Electronics ,Vol.25, No. 6, pp. 1527-1536, Jun 2010. 
[6] Ali M. Eltamaly "A Modified Harmonics Reduction Technique of Three-Phase Controlled Converter" IEEE Transactions on Industrial Electronics, Vol. 55, No. 3, pp.1190-1197, March 2008.

[7] K. M. Tsang and W. L. Chan "Active Power Factor Correction Using Nonlinear Control," Electric Power Components and Systems, Vol. 33, No. 9, pp. 973-983, September 2005.

[8] Rahul Khopkar, S.M. Madan, Masoud HaJiaghajani and Hamid A. Toliyat, "A Low-Cost BLDC Motor Drive using Buck-Boost converter for Residential and Commercial Applications," IEEE International Conference on Electric Machines and Drives, IEMDC'03, Vol. 2, pp. 1251- 1257, 2003.

[9] Bhim Singh and Vashist Bist "A Reduced Sensor PFC Bridgeless Flyback Converter Fed BLDC Motor Drive," Electric Power Components and Systems, Vol. 41, No. 11, pp. 1114-1128, August 2013.

[10] Pradeep M Patil and Sanjay and L Kurkute "Speed Control of Three Phase Induction Motor Using Single Phase Supply Along With Active Power Factor Correction," ACSE Journal, Vol. 6, Issue 3,pp. 23-32 Oct. 2006.

[11] G. Chu, C. K. Tse, S. C. Wong, and Siew-Chong Tan, "A unified approach for the derivation of robust control for boost PFC converters," IEEE Transactions on Power Electronics, vol. 24, no. 11, pp. 2531-2544, Nov. 2009.

[12] S. A. Davari, D. A. Khaburi, R. Kennel, "An improved FCS-MPC algorithm for induction motor with imposed optimized weighting factor", IEEE Transactions on Power Electronics, Vol. 27, pp. 1540 - 1551, 2012.

[13] J.-M.Retif, " Predictive Current Control for an Induction Motor ", Power Electronics Specialists Conference, PESC 2008. IEEE, PP 3463 - 3468, June 2008

[14] H. Abu-Rub, J. Guzinski, J. Rodriguez, R. Kennel, P. Cortes, "Predictive current controller for sensorless induction motor drive", IEEE International Conference on Industrial Technology (ICIT), pp. 1845 - 1850, 2010.

[15] S. A. Davari, D. A. Khaburi, "Sensorless predictive torque control of induction motor by means of reduced order observer", 2nd IEEE Power Electronics, Drive Systems and Technologies Conference (PEDSTC), pp. 484-488, 2011.

[16] Wanfeng Zhang, Guang Feng, Yan-Fei Liu and Bin Wu," New Digital Control Method for Power Factor Correction", IEEE Transactions on Industrial Electronics, Vol. 53, no: 3, pp. 987 - 990, 2006.

[17] M. Fu and Q. Chen, "A DSP base controller for power factor correction in a rectifier circuit," in Proc. IEEE Appl. Power Electron. Conf., pp. 144-149, 2001.

[18] A. Prodic, D. Maksimovic, and R.W. Erikson, "Dead-Zone digital controller for improved dynamic response of power factor correction," in Proc. IEEE Appl. Power Electron Conf., pp.382-388, 2003. 
[19] J.Chen, A.Prodić, R.W.Erickson and D.Maksimović, "Predictive Digital Current Programmed Control," IEEE Transaction on Power Electronics, Vol. 18, No.1, pp.411-419, 2003.

[20] S. Bibian and H. Jin, "digital control with improved performance for boost power factor correction circuits," in Proc. Appl. Power Electron. Comf., pp137-143, 2001.

[21] S.Bibian and H.Jin, "High performance predictive dead-beat controller for DC power," in proc. Appl. Power Electron. Conf., pp67-73, 2001.

\section{Appendix A,}

The induction motor parameters are as follows:

\begin{tabular}{|l|c|}
\hline $\begin{array}{l}\text { Rated power, Rated voltage, Rated current, } \\
\text { No. of poles }\end{array}$ & $1.5 \mathrm{hp}, 380 \mathrm{v}, 2-8 \mathrm{~A}, 4$ \\
\hline Stator resistance, Rotor resistance & $7.4826,3.834$ \\
\hline Mutual inductance, Stator leakage inductance & $0.4114 \mathrm{H}, 0.0221 \mathrm{H}$ \\
\hline Rotor leakage inductance & $0.0221 \mathrm{H}$ \\
\hline $\begin{array}{l}\text { Rated speed, Moment of inertia, Rated } \\
\text { torque }\end{array}$ & $1400 \mathrm{rpm}, 0.035 \mathrm{~kg} . \mathrm{m} 2,7.5 \mathrm{Nm}$ \\
\hline
\end{tabular}

